\title{
The evolving field of kinase inhibitors in thyroid cancer
}

\author{
V. Marotta ${ }^{\mathrm{a}, *}$, C. Sciammarella ${ }^{\mathrm{a}}$, M. Vitale $^{\mathrm{b}}$, A. Colao $^{\mathrm{a}}$, A. Faggiano $^{\mathrm{a}, \mathrm{c}}$ \\ ${ }^{a}$ Department of Clinical Medicine and Surgery, Section of Endocrinology, Federico II University of Naples, Italy \\ ${ }^{\mathrm{b}}$ Department of Medicine and Surgery, University of Salerno, Baronissi, Italy \\ ${ }^{\mathrm{c}}$ Endocrinology, National Cancer Institute, Fondazione G. Pascale, Naples, Italy
}

Accepted 19 August 2014

\section{Contents}

1. Introduction.

2. Rationale for the use of KIs in thyroid cancer.

3. Clinical trials of KIs in thyroid cancer

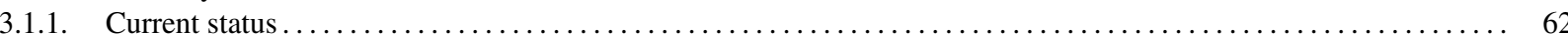

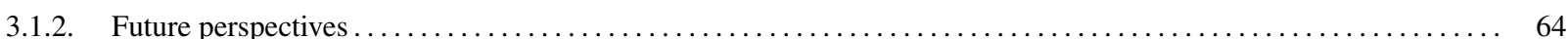

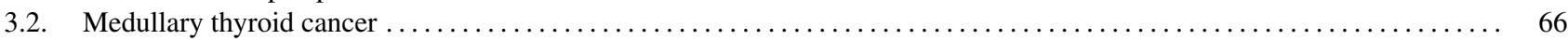

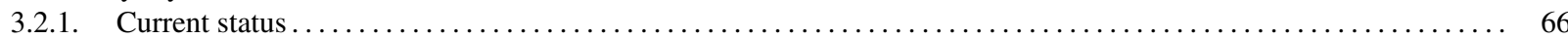

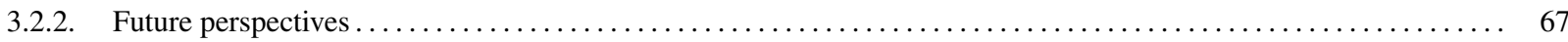

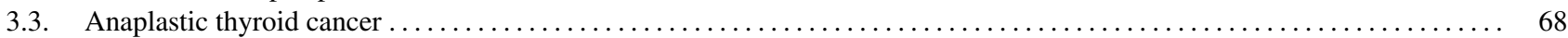

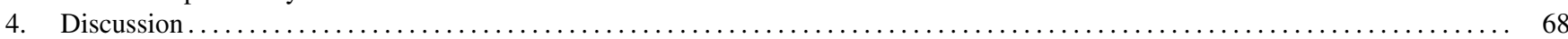

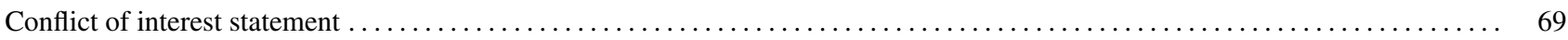

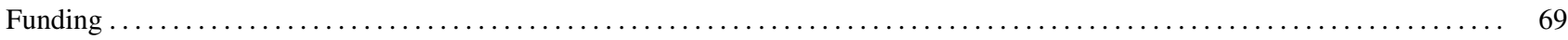

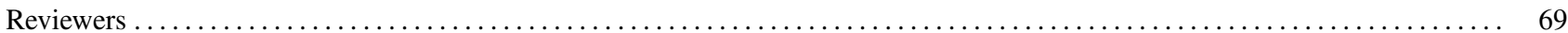

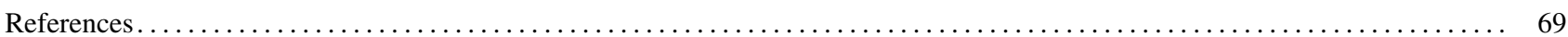

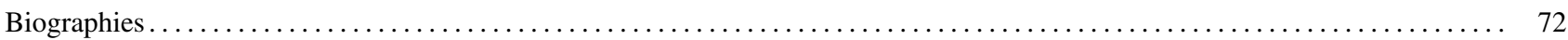

\begin{abstract}
Most of the genetic events implicated in the pathogenesis of thyroid cancer (TC) involve genes with kinase activity. Thus, kinase inhibitors (KIs) are very relevant in this field. KIs are considered the most suitable treatment for patients with iodine-refractory differentiated TC; these patients comprise the subgroup with the poorer prognosis. To date, only sorafenib has been approved for this indication, but promising results have been reported with several other KIs. In particular, lenvatinib has demonstrated excellent efficacy, with both progression-free survival and objective tumour response being better than with sorafenib. Despite being considered to be well tolerated, both sorafenib and lenvatinib have shown a remarkable toxicity, which has led to dose reductions in the majority of patients and to treatment discontinuation in a significant proportion of cases. The role of KIs in differentiated TC may be revolutionised by the finding that selumetinib may restore a clinical response to radioactive iodine (RAI). Vandetanib and cabozantinib have been approved for the treatment of advanced, progressive medullary TC (MTC). Nevertheless, the toxicity of both compounds suggests their selective use in those patients with strong disease progression. Treatment with the mTORinhibitor everolimus, alone or in combination with somatostatin analogues, should be studied in metastatic MTC patients with slow progression of disease, these representing the vast majority of patients. KIs did not significantly impact on the clinical features of anaplastic TC (ATC). (c) 2014 Elsevier Ireland Ltd. All rights reserved.
\end{abstract}

Keywords: Thyroid cancer; Cancer therapy; Protein kinases; Kinase inhibitors; Anti-angiogenetic therapy

\footnotetext{
* Corresponding author at: Department of Clinical Medicine and Surgery, Section of Endocrinology, Via Sergio Pansini, 80131 Naples, Italy. Tel.: +39 817464737; fax: +39815465443 .

E-mail address: vinc.endo@libero.it (V. Marotta).
} 


\section{Introduction}

Thyroid cancer is a malignancy with a rapidly growing public health relevance. Apart from being the most common endocrine tumour, its incidence in Western countries has progressively increased in the last decades [1,2]. Typically, endocrine cancers are poorly responsive to DNA-damaging treatments [3]. Particularly, cytotoxic systemic chemotherapies have demonstrated limited efficacy in advanced thyroid carcinomas, with response rates of $25 \%$ or less [4]. Thus, treatment of aggressive forms of thyroid tumours is challenging, and the validation of innovative therapies is mandatory in this field. Thyroid cancer involves neoplasms arising from epithelial follicular cells, including papillary thyroid carcinoma (PTC), follicular thyroid carcinoma (FTC), poorly differentiated thyroid carcinoma (PDTC), and anaplastic thyroid cancer (ATC), whereas medullary thyroid carcinoma (MTC) derives from parafollicular calcitonin-secreting C cells. PTC and FTC are classified as differentiated thyroid cancers (DTCs) and represent the vast majority of thyroid carcinomas (80-90\%) [5]. Conventional treatment of DTC is based on a combined approach consisting in total thyroidectomy and, in selected cases, radioactive iodine (RAI) followed by suppression of thyroid-stimulating hormone (TSH) $[5,6]$. This approach is highly effective, as DTC usually has an excellent prognosis with a 10-year disease-related survival of $85 \%$ [7]. Nevertheless, about $5 \%$ of DTC patients develop an aggressive disease with distant metastases and loss of I-131 avidity. Patients with RAI-resistant DTC are generally not responsive to conventional chemotherapy and have a long-term overall survival of $10 \%$ [8]. MTC accounts for approximately $5 \%$ of thyroid cancers [1]. Given its neuroendocrine origin, MTC is not responsive to either RAI or TSH suppression. Thus, surgery is the only curative approach in such cases. Nevertheless, $60-80 \%$ of MTC patients have metastatic disease at the time of diagnosis, and only half of these subjects become disease-free after surgery [9]. Progressive forms of metastatic MTC are generally poorly responsive to chemotherapy and exhibit a 5-year survival rate of less than 50\% [10]. ATC accounts for less than $2 \%$ of thyroid malignancies, but it is the most aggressive subtype of thyroid cancer, being responsible for 14-39\% of deaths related to thyroid tumours [11]. Treatment of ATC is not yet standardised and is mainly empirical and multimodal, including surgery, chemotherapy and radiotherapy [12]. Nevertheless, prognosis of ATC patients is poor, with a mean survival of less than 6 months after diagnosis [13]. PDTC is a controversial entity showing features intermediate between those of DTC and ATC at both the histological and clinical levels [14]. Thus, PDTC patients have a worse prognosis than subjects with classical DTC [15].

In recent years treatment of aggressive forms of endocrine cancer has been revolutionised by the use of kinase inhibitors (KIs). These are small organic molecules that interfere with the interaction between the kinase domain and adenosine triphosphate (ATP) or other mechanisms such as allosteric inhibitors, thereby inhibiting phosphorylation of the kinase and activation of downstream signalling pathways [16] (see Table 1 for KIs referred to in this paper and their molecular targets). The majority of KIs available in clinical practice are non-selective, being active against several molecular targets [17]. This implies that these compounds have a multimodal action. Indeed, anticancer activity of KIs is based on a double mechanism: a direct anti-proliferative function achieved by blocking molecules involved in intracellular pathways of survival, proliferation and growth, and an anti-angiogenic function performed by halting the activation of specific receptors of angiogenic factors, thus inhibiting intracellular pathways that stimulate angiogenesis [18].

\section{Rationale for the use of KIs in thyroid cancer}

The concept of targeted therapy is a perfect fit for thyroid cancer. Indeed, genetic alterations having a demonstrated oncogenic role have been detected in a significant proportion of thyroid malignancies [19]. Typically, these genetic abnormalities are mutually exclusive, so they can be considered as crucial pathogenetic events [20]. Most of these genetic events involve genes with kinase activity and are implicated in the MAP kinases and/or the PI3K/Akt/mTOR signalling cascades [21]. Activation of these pathways leads to neoplastic transformation and progression [22]. Hence, thyroid cancer represents an ideal model for testing anti-cancer activity of KIs. The T1799A transverse point mutation of BRAF, which is a serine-threonine kinase, is the most common genetic alteration in PTC, being detected in approximately $45 \%$ of these neoplasms $[23,24]$. The mutation results in the V600E amino-acidic substitution leading to the constitutive induction of the kinase activity with aberrant activation of the MAP kinases pathway [25-27]. Furthermore, $\mathrm{BRAF}^{\mathrm{V} 600 \mathrm{E}}$ has been detected in $20-40 \%$ of PDTCs and $30-40 \%$ of ATCs [28-31]. The presence of BRAF mutation in both PTCs and less differentiated forms of thyroid cancer of follicular origin (PDTC, ATC) suggests the hypothesis of a critical role of this mutation in PTC progression. To date, the crucial role of mutated BRAF in promoting the biological and clinical evolution of PTC has been widely ascertained. From the molecular point of view, BRAF mutation is associated with decreased expression of mRNAs for proteins that induce differentiation of follicular cells, such as the sodium iodide symporter and the TSH receptor [32], so it promotes tumour dedifferentiation. Clinically, mutated BRAF is associated with clinico-pathological features having a negative prognostic impact, RAI unresponsiveness and increased rates of disease recurrence and mortality [33,34]. A recent study by Guerra et al. [35] demonstrated that the percentage of mutated alleles within the tumour mass correlates with a poorer outcome among BRAF-positive PTC cases. Chromosomal rearrangements of RET, which encodes a tyrosine-kinase receptor, have been detected in a significant proportion of PTCs [36,37]. These genetic events lead to the constitution 
Table 1

Molecular targets of the kinase-inhibitors mentioned in the text.

\begin{tabular}{|c|c|c|c|c|c|c|c|c|c|c|c|c|c|c|}
\hline Compound & RET & BRAF & RAF-1 & mTOR & c-MET & c-Kit & VEGFR1 & VEGFR2 & VEGFR3 & PDGFR $\alpha$ & PDGFR $\beta$ & EGFR & FGFR1 & MEK \\
\hline Motesanib & $X$ & & & & & $X$ & $X$ & $X$ & $\mathrm{X}$ & $X$ & & & & \\
\hline Axitinib & & & & & & & $\mathrm{X}$ & $\mathrm{X}$ & $\mathrm{X}$ & & & & & \\
\hline Imatinib & $\mathrm{X}$ & & & & & $X$ & & & & $\mathrm{X}$ & $\mathrm{X}$ & & & \\
\hline Sorafenib & & $X$ & $X$ & & & & & $\mathrm{X}$ & $\mathrm{X}$ & & $\mathrm{X}$ & & & \\
\hline Sunitinib & $X$ & & & & & $X$ & $X$ & $X$ & & $X$ & $X$ & & & \\
\hline Vandetanib & $\mathrm{X}$ & & & & & & & $X$ & $\mathrm{X}$ & & & $\mathrm{X}$ & & \\
\hline Lenvatinib & & & & & & $X$ & $X$ & $X$ & $\mathrm{X}$ & & $X$ & & $X$ & \\
\hline Pazopanib & & & & & & $X$ & $X$ & $X$ & $\mathrm{X}$ & $X$ & $\mathrm{X}$ & & & \\
\hline Cabozantinib & $\mathrm{X}$ & & & & $\mathrm{X}$ & & $\mathrm{X}$ & $\mathrm{X}$ & & & & & & \\
\hline Vemurafenib & & $\mathrm{X}^{*}$ & & & & & & & & & & & & \\
\hline Dabrafenib & & $\mathrm{X}^{*}$ & & & & & & & & & & & & \\
\hline Everolimus & & & & $X$ & & & & & & & & & & \\
\hline Selumetinib & & & & & & & & & & & & & & $X$ \\
\hline
\end{tabular}

* Mutant BRAF ${ }^{\mathrm{V} 600 \mathrm{E}}$.

of chimeric genes, namely RET/PTC, which are ectopically expressed in thyroid follicular cells and promote neoplastic transformation through the activation of both MAP kinases and PI3K/Akt/mTOR pathways [38,39]. Besides, RET has a prominent role in the molecular pathogenesis of MTC. Indeed, germline RET point mutations are responsible for hereditary forms of MTC [40], while approximately 50\% of sporadic MTCs harbour activating RET mutations [41]. The crucial pathogenetic role of RET in this field has been widely supported by studies on transgenic mice $[42,43]$. More importantly, there is a clear correlation between genotype and tumour behaviour. A codon 918 somatic RET mutation, which affects the catalytic domain of the receptor, predicts a high rate of metastasis and death in sporadic forms of MTC [44]. The mutation can also be inherited, thus inducing multiple endocrine neoplasia $2 \mathrm{~B}$ syndrome which is characterised by precocious and aggressive MTC, even treated with prophylactic surgery in the first year of life [45]. Besides single point mutations and chromosomal rearrangements, genetic amplification or copy number gain of genes with kinase activity has been reported in thyroid cancer [21]. A recent study performed by Liu et al. [46], focusing on FTC and ATC, identified copy number gains of several tyrosinekinase receptors (EGFR, PDGFR $\alpha$ and $\beta$, VEGFR1 and 2, c-MET, and c-KIT) and other intracellular kinases (PDK1, Akt-1, Akt-2, PIK3CA, and PIK3CB). The pathogenetic role of these genetic alterations was demonstrated in the same paper, where the activation of the downstream signalling pathways was observed, as attested by the increased phosphorylation of AKT and ERK. Interestingly, copy-number gains of these genes were more frequent in ATC than in FTC, thus suggesting a role of these genetic events in the progression and aggressiveness of thyroid cancer. Furthermore, over-expression of receptors with tyrosine kinase activity (EGFR, c-Met, and FGFR4) has been found also in MTC [47-49]. Pre-clinical data providing crucial support for the use of KIs in thyroid cancer have been published by Xing and his research group. Indeed, these workers have assessed activity of several KIs in thyroid cancer cell lines carrying or not carrying mutations in those molecular pathways specifically targeted by the tested agents. The authors clearly showed that the anti-proliferative effect of the compounds studied was mostly dependent on the presence of genetic alterations involving their own targeted intracellular cascades [50-52]. This genetic dependency has been interpreted by the authors as being related to the driving role of genetic alterations involving the MAP kinases and the PI3K/Akt/mTOR pathways, which induce addiction in those cells harbouring the mutation. As aforementioned, the anti-cancer activity of KIs is related not only to the anti-proliferative function but also to the anti-angiogenetic activity. The pathogenetic role of neo-angiogenesis has been demonstrated in several types of endocrine tumours, including thyroid cancer [53-57]. In particular, elevated expression of angiogenic factors - including VEGF, EGF, and their receptors - has been detected in cell lines, tumour tissues and serum of patients affected with thyroid cancer of follicular origin and was found to be strongly correlated with tumour behaviour [58-61]. Furthermore, a single nucleotide polymorphism of the VEGFA gene, the so-called rs699947, has been found to be associated with the development and aggressiveness of thyroid cancer in men [62]. In PTC, the intensity of VEGF expression correlates with a higher risk of metastasis and recurrence, a shorter disease-free survival, and BRAF mutation status (which is considered an independent negative prognostic factor) [63-65]. These observations strongly suggest that striking angiogenetic pathways by the use of KIs represents a feasible approach for the treatment of thyroid cancer.

\section{Clinical trials of KIs in thyroid cancer}

\subsection{Differentiated thyroid cancer}

\subsubsection{Current status}

Among DTC patients the need for innovative therapies is limited mainly to those who are refractory to RAI. Since 2008, several studies of KIs in RAI-refractory DTC have been published (results reported in Table 2). Although few data are available so far, guidelines from the American 
Table 2

Efficacy of kinase-inhibitors for the treatment of iodine-refractory DTC in available trials.

\begin{tabular}{|c|c|c|c|c|}
\hline KI [Ref.] & Type of study & N. of patients & Best TR (\%) & mPFS (months) \\
\hline Motesanib [68] & II & 93 & CR 0 PR 14 SD 67 & 10 \\
\hline Axitinib [69] & II & 45 & CR 0 PR 31 SD 42 & - \\
\hline Axitinib [70] & II & 32 & CR 0 PR 41 SD 18 & - \\
\hline Sunitinib [72] & II & 29 & CR 3 PR 24 SD - & - \\
\hline Sorafenib [73-77] & II, retrospective & 122 & CR 0 PR $15-30$ SD 34-71 & $9-21$ \\
\hline \multirow[t]{2}{*}{ Sorafenib $[78]$} & \multirow[t]{2}{*}{ III, RCT, placebo controlled } & 207 sorafenib & CR 0 PR $12.2^{*}$ SD 42 & $10.8^{*}$ \\
\hline & & 210 placebo & CR 0 PR 0.5 SD 33 & 5.8 \\
\hline Lenvatinib [81] & II & 58 & CR 0 PR 54 SD 46 & 13.3 \\
\hline \multirow[t]{2}{*}{ Lenvatinib [82] } & \multirow[t]{2}{*}{ III, RCT, placebo controlled } & \multirow[t]{2}{*}{$392(2: 1$ to lenvatinib or placebo) } & CR 1.5 PR 63.2 SD - & $18.3^{*}$ \\
\hline & & & CR 0 PR 1.5 SD - & 3.6 \\
\hline Pazopanib [83] & II & 37 & CR 0 PR 49 SD 46 & 11.7 \\
\hline \multirow[t]{2}{*}{ Vandetanib [85] } & \multirow[t]{2}{*}{ II, RCT, placebo controlled } & 72 vandetanib & CR 0 PR 8 SD - & $11.1^{*}$ \\
\hline & & 73 placebo & CR 0 PR 5 SD - & 5.9 \\
\hline \multirow[t]{2}{*}{ Vemurafenib [90] } & \multirow[t]{2}{*}{ II } & 26 Kis-naive & CR 0 PR 35 SD 23 & 15.6 \\
\hline & & 25 Kis-pretreated & CR 0 PR 26 SD 10 & 6.8 \\
\hline Everolimus [99] & II & 24 & CR 0 PR 4.2 SD 95.8 & 10.75 \\
\hline Everolimus [100] & II & 33 & CR 0 PR 3 SD 55 & 16 \\
\hline Everolimus + sorafenib [102] & II & 19 & CR 0 PR 57.9 SD 36.8 & - \\
\hline Selumetinib [108] & II & 39 & CR 0 PR 3 SD 54 & 8 \\
\hline
\end{tabular}

Abbreviations: KI, kinase-inhibitor; Ref., reference; N., number; TR, tumour response; Mpfs, median progression-free survival; CR, complete response; PR, partial response; SD, stable disease; RCT, randomised controlled trials.

* Difference statistically significant.

Thyroid Association [6] have recommended the use of KIs in this clinical setting since 2009. Despite still being a controversial issue, the demonstration of disease progression represents the main indication for referring iodine-refractory DTC patients for medical treatment $[66,67]$. Thus, trials that selectively enrolled patients with a documented progressive disease should be considered as having a higher clinical relevance, rather than those not requiring disease progression before entry. The first published paper about use of KIs in this field was a phase-II trial with motesanib [68], which targets the tyrosine-kinase receptors RET, c-Kit, PDGFR $\alpha$ and all three types of VEGFRs. Notably, only patients showing disease progression in the previous 6 months were enrolled. A rate of $14 \%$ of subjects had a partial response (PR) and $67 \%$ had stable disease (SD) with a median PFS (progression-free survival) of 10 months. Axitinib targets mainly VEGFRs, thus exhibiting a predominant anti-angiogenic action. A phase-II clinical trial by Cohen et al. [69], including 45 patients affected with DTC, showed PR in $31 \%$ and SD in $42 \%$ of these subjects. Nevertheless, the study was limited by the inclusion of patients with heterogeneous disease aggressiveness, as the evidence of radiological progression was not required before entry. By contrast, a recent contribution presented at the American Society of Clinical Oncology (ASCO) 2014 meeting has assessed the activity of axitinib in 32 iodine-refractory DTC patients having documented disease progression [70]. Authors reported objective tumour response in $41 \%$ of subjects, thus suggesting a meaningful role for axitinib in this clinical setting. Sunitinib targets RET, c-Kit, VEGFR1 and 2, and PDGFR $\alpha$ and $\beta$. It seems to be effective against endocrine cancers as it has been approved for the treatment of advanced pancreatic neuroendocrine tumours [71]. Nevertheless, the efficacy of sunitinib for the treatment of DTC has been studied only in one phase-II clinical trial, where patients were included independently of the demonstration of disease progression [72]. Authors reported a case of complete response to treatment in one out of 29 patients affected with DTC, while seven more subjects (24\%) achieved PR. SD was obtained in $48 \%$ of the overall study population which included also six patients with MTC. The most studied KI for the treatment of RAI-refractory DTC is sorafenib. Its specificity was suggested by the inhibition of the RAF kinases, which are strikingly involved in the development and progression of thyroid cancer [20]. From 2008 to 2012, several studies with heterogeneous designs and inclusion criteria have assessed the activity of sorafenib in this field [73-77]. A meta-analysis of these papers, including a total of 122 patients, showed PR rates between $15 \%$ and $30 \%$ and SD rates from $34 \%$ to $71 \%$ with a median PFS ranging from 9 to 21 months. These findings led to the first phase-III trial of any KI in DTC. The DECISION study (NCT00984282) was a randomised, placebo-controlled, double-blind, multicentre, international study enrolling KIs-naive RAI-refractory DTC patients showing disease progression in the previous 14 months. Results from the DECISION trial have been recently published [78]. Overall, 417 patients were enrolled (207 to sorafenib and 210 to placebo). Tumour histology assessed by independent review revealed 57\% PTC, 25\% FTC, and 10\% PDTC. A significant improvement in median PFS was observed in the sorafenib group as compared with placebo (10.8 versus 5.8 months; HR $0.58,95 \%$ CI $0.45-0.75, P<0.0001)$, and this was the primary endpoint of the study. Median overall survival (OS) was not reached in either group, and, given that $70 \%$ of placebo patients crossed over, it is likely that no differences would have been found. PR rate in the sorafenib versus 
placebo arm was $12.2 \%$ and $0.5 \%(P<0.0001)$, while the SD rate lasting more than 6 months was $42 \%$ and 33\%, respectively. Based on these efficacy results, sorafenib has become the first KI approved by the US Food and Drug Administration (FDA) for the treatment of progressive RAIrefractory DTC. The most frequent treatment-related adverse events reported in the DECISION trial were hand-foot skin reaction $(76.3 \%)$, diarrhoea $(68.6 \%)$, alopecia $(67.1 \%)$, rash or desquamation $(50.2 \%)$, fatigue $(49.8 \%)$, weight loss (46.9\%), and hypertension (40.6\%). It should be noted that, despite being mostly of grade 1 or 2 , these toxicities led to dose interruptions, reductions, or withdrawals in $66.2 \%$, $64.3 \%$, and $18.8 \%$ of patients, respectively. This represents a crucial issue for the clinical use of sorafenib, as many patients with iodine-refractory DTC are asymptomatic, even if disease progression is documented. Lenvatinib targets RET, c-Kit, VEGFRs, FGFR1 and PDGFR $\beta$. Inhibition of human xenograft tumour growth by lenvanitib was observed at doses as low as 1.0 and $10.0 \mathrm{mg} / \mathrm{kg}$, suggesting greater efficacy than the majority of pre-tested KIs [79]. Recently, an inhibitory effect of lenvatinib on both oncogenic signal and cell growth has been demonstrated in thyroid cancer cell lines harbouring RET fusion genes [80]. Exciting results for lenvatinib in DTC were first obtained in a phase-II trial of 58 RAI-refractory patients [81] with progressive disease, where authors reported $54 \%$ of PR and $46 \%$ of SD. These data led to a randomised, placebo-controlled, double-blind, multicentre, international phase-III study enrolling RAI-refractory DTC patients with documented disease progression in the previous 13 months (SELECT trial, NCT01321554). Results from the SELECT trial have recently been presented at the ASCO 2014 meeting [82]. Overall, 392 patients were enrolled and randomised with a $2: 1$ ratio to lenvatinib or placebo. A significant improvement in median PFS was observed in the lenvatinib group as compared with placebo (18.3 versus 3.6 months; HR 0.21 , 95\% CI $0.14-0.31, P<0.0001$ ), thus achieving the primary endpoint of the study. Given that cross-over was allowed for patients receiving placebo upon progression, median OS was not reached. Notably, lenvatinib obtained an objective tumour response in $64.7 \%$ of patients, including four subjects $(1.5 \%)$ who achieved complete responses. According to these results, lenvatinib seems to be more effective in both improving PFS (18.3 versus 10.8 months) and obtaining an objective tumour response $(64.7 \%$ versus $12.2 \%)$ as compared with sorafenib. These data are even more meaningful if it is considered that the SELECT trial enrolled patients with more advanced disease who had been already treated with KIs, whereas the DECISION trial did not allow previous KI treatment. The most frequent treatment-related adverse events reported in the SELECT trial were hypertension (68\%), diarrhoea (59\%), appetite decrease (50\%), weight loss $(46 \%)$, and nausea $(41 \%)$. As with sorafenib, the reported toxicities were mainly grade 1 or 2 , but led frequently to dose reductions or withdrawals (78.5\% and $14.2 \%$, respectively). Pazopanib is a KI targeting c-Kit, VEGFRs and PDGFRs. Like axitinib, its activity is expected to be primarily anti-angiogenetic. In 2010, a multicentre phase-II trial headed by the Mayo Clinic [83] tested activity of pazopanib in 37 RAI-refractory DTC patients. Distinctive features of the study were that up to two previous systemic treatments (including KIs) were allowed, and radiographic progression of disease was requested in the 6 months preceding the enrolment. These criteria led to the selection of a population of highly aggressive RAI-refractory DTC cases. Notably, authors found a PR rate of $49 \%$, while $46 \%$ of patients experienced SD. Furthermore the likelihood of a response lasting more than 1 year was calculated to be $66 \%$. Notably, PRs were higher in FTC than in PTC (73\% versus 33\%). Vandetanib is a KI that targets RET, VEGFR2, VEGFR3, and EGFR. As discussed below, it has been already approved by the FDA for the treatment of adults with symptomatic or progressive MTC [84]. In 2012, Leboulleux et al. [85] have performed a randomised, multicentre, placebo-controlled, phase-II trial of vandetanib in RAI-refractory DTC, with no requirement of disease progression for enrolment. Although no significant difference was found in radiological response between groups, authors demonstrated a significant improvement of PFS in the treatment group compared with placebo (11.1 versus 5.9 months; HR 0.63 , 60\%CI $0.54-0.74$, one-sided $P=0.008$; 95\%CI 0.43-0.92, two-sided $P=0.017$ ), thus achieving the primary endpoint of the study. This discrepancy could be related to at least two issues: (a) the inclusion of patients with heterogeneous disease aggressiveness, and (b) the use of RECIST criteria, which are based solely on the dimensional assessment, thus excluding the evaluation of tumour necrosis, a recognised marker of response to targeted therapies [86]. Another relevant finding of the study was that the positive effect of vandetanib on PFS was stronger for the PTC histotype. It was concluded that vandetanib may be a useful tool for the long-term control of patients with iodine-refractory DTC (especially PTC). Nevertheless, toxicity of vandetanib was worse than that of other KIs. Indeed, adverse events leading to discontinuation were detected in $33 \%$ of the vandetanib group, QTc prolongation and diarrhoea being the most frequent. Furthermore, two drug-related fatal events (haemorrhage from skin metastases and pneumonia) were reported. Thus, the toxicity profile hampers the long-term administration of vandetanib in this clinical setting.

\subsubsection{Future perspectives}

In recent years a new class of pyridoimidazolonecontaining molecules, including vemurafenib and dabrafenib, has been introduced into clinical trials. These drugs act as potent and selective inhibitors of the BRAFV600E oncogene, and this provides the rationale for testing their efficacy in tumours harbouring the BRAF mutation. The responsivity to vemurafenib and dabrafenib in melanoma patients harbouring mutated BRAF suggests that these agents may be effective also in advanced thyroid cancer harbouring BRAF mutation $[87,88]$. Recently, an anecdotal 
experience about use of vemurafenib in three patients affected with RAI-refractory PTC, who were positive for the BRAF mutation, has been published [89]. A radiological response was demonstrated in all subjects. In particular, one patient achieved PR with a time to progression of 11.7 months, whereas SD was observed in the remaining two subjects, with a time to progression of 13.2 and 11.4 months, respectively. This led to an open-label, multicentre, phase-II trial (NCT01286753) about vemurafenib in RAI-refractory PTC patients harbouring the BRAFV600E mutation; this trial is still ongoing, but has recently terminated recruitment. Preliminary results have been presented at the European Cancer Congress (ECC) 2013 meeting [90]. Among the 51 patients enrolled, two cohorts were individualised, on the basis of the previous assumption of KIs (naive or pre-treated). PR was observed in $35 \%$ of the KIs-naive patients and in $26 \%$ of the pre-treated patients, whereas clinical benefit $(\mathrm{PR}+\mathrm{SD})$ was observed in 58\% and 36\%, respectively. Furthermore, PFS was higher in the naive group, as compared with the patients pre-treated with KIs (15.6 and 6.8 months, respectively). Treatment was almost well-tolerated - rash, fatigue, weight loss, and increased bilirubin being the most common adverse events. Hence, authors concluded that vemurafenib has a relevant anti-tumour activity in PTC patients harbouring BRAFV600E, especially in the subgroup without previous KI treatment. This could be related - at least in part - to the positive selection of neoplastic clones without the BRAF mutation that could occur in patients pre-treated with KIs, where alternative intracellular pathways are activated in order to circumvent the molecular blockade, thus promoting the failure of the targeted therapy [91]. Nevertheless, the trial did not require demonstration of disease progression before entry, and this reduces its clinical relevance. Everolimus is a selective inhibitor of mTOR, a serine/threonine kinase that plays an important role in cellular growth and homeostasis [92]. Recent studies have found that the mTOR pathway is involved in the pathogenesis of several endocrine cancers such as neuroendocrine tumours and adrenocortical carcinoma [93-98]. Everolimus has been approved recently for the treatment of advanced pancreatic neuroendocrine tumours [84]. In December 2013, Lim et al. [99] published the first clinical trial of the activity of everolimus in aggressive forms of thyroid cancer in cases where RAI was ineffective or inappropriate. Thus, thyroid malignancies of any histology were included. Importantly, only patients having progressive disease were enrolled. Despite the fact that data about specific histotypes were not precisely reported, disease control was obtained in the vast majority of DTC patients, with a median PFS of 10.75 months. Nevertheless, PR was reported in only one DTC subject. Another phase-II trial about everolimus in RAI-refractory thyroid cancer (including MTC and ATC) had already been presented at the ASCO meeting in 2013 [100]. Thirty-three DTC patients with documented disease progression in the previous 6 months were enrolled. PFS, which was the primary endpoint, was 16 months. Consistently with reports by Lim et al., only one patient experienced PR, whereas $18(55 \%)$ and ten (30\%) achieved SD lasting 6 and 12 months, respectively. Activation of autophagy without markers of apoptosis was detected in three patients subjected to sequential biopsies, and this is consistent with the increasing trend to achieve disease stability rather than an objective tumour shrinkage. Carracedo et al. [101] has demonstrated that mTOR inhibition can activate MAPK through a PI3K-dependent feedback loop in human cancer, thus inducing therapeutic escape. Hence, a combination of everolimus with KIs targeting alternative signalling pathways may yield both an improved efficacy and a longer response. A phase-II trial (presented at the ASCO meeting 2013) has assessed the combination of sorafenib (400 mg twice a day) and everolimus (10 mg daily) in progressive RAI-refractory thyroid cancer, excluding the anaplastic histotype [102]. Among DTC patients, PR rates were higher than those reported for sorafenib as a single agent, the Hurtle cell FTC variant being the most responsive histotype $(\mathrm{PR}=67 \%)$. Nevertheless, authors reported the occurrence of several grade- 4 adverse events, which were likely related to the combined study treatment. In past years, several medical treatments - including lithium [103] and retinoids [104] - have been tested in order to restore RAI avidity in patients with iodine-refractory DTC, but no relevant results were obtained. Selumetinib is a selective inhibitor of MEK, which is a dual-specificity kinase having both serine-threonine and tyrosine kinase activity. Importantly, MEK represents the primary downstream target of B-RAF [105]. In 2007, Liu et al. demonstrated that targeting the MAP kinases cascade through a specific MEK inhibitor could restore expression of thyroid iodide-metabolising enzymes in rat cells harbouring the BRAFV600E mutation [106]. This insight was further empowered by Chakravarty et al., who published pre-clinical data from mouse models in which switching off downstream signalling from BRAF has led to the regain of the tumour's RAI avidity [107]. These findings led to a growing interest in selumetinib as a feasible therapeutic tool for thyroid cancer. To date, anti-tumour activity of selumetinib in progressive iodine-refractory DTC has been assessed by Hayes et al. [108], with unsatisfactory results. Indeed, the authors found a higher rate of disease progression (28\%) and a shorter PFS (8.25 and 2.75 months in patients with and without BRAF mutation, respectively), as compared with the majority of other KIs. Nevertheless, Ho et al. [109] have recently published a trial assessing the possible role of selumetinib in resensitising DTC to RAI. Patients were treated with selumetinib $75 \mathrm{mg}$ twice daily for 4 weeks and were than re-evaluated with an iodine-124 positron-emission tomography (PET) scan. Restoration of RAI uptake was observed in eight out of 24 subjects (40\%). These patients were subjected to RAI treatment and all of them achieved clinical benefit with confirmed PR in five and $\mathrm{SD}$ in three patients. Notably, these responses lasted more than 6 months in the majority of subjects (seven patients). Hence, selumetinib may restore RAI avidity in a relevant proportion of RAI-refractory DTC patients, thus retrieving 
the efficacy of RAI. The possible role of selumetinib in enhancing tumour responsiveness to RAI led to a phase-II study comparing the efficacy of the combination selumetinib (administered in a 5-week course, $75 \mathrm{mg}$ twice daily) with adjuvant RAI versus placebo with single-adjuvant RAI in determining remission of DTC with a high risk of treatment failure (primary tumour $>4 \mathrm{~cm}$, or gross extra-thyroid extension, or one lymph node $>1 \mathrm{~cm}$, or five or fewer lymph nodes of any size) (NCT01843062). Currently, this trial is actively recruiting.3.2 Medullary thyroid cancer.

\subsection{Medullary thyroid cancer}

\subsubsection{Current status}

Results from available clinical trials on the use of KIs in advanced MTC are reported in Table 3. Given its ability to inhibit RET at low concentrations [110], imatinib was the first KI assessed in this field. Nevertheless, results from two small-sized studies showed no reduction in tumour size, although several subjects had SD [111,112]. Axitinib blocks VEGFRs but not RET. This may explain why, in the Cohen's trial [69], results achieved in the 11 patients with medullary histology were poorer than those in DTC subjects. In particular, disease control rate (PR and SD) of the MTC cohort was less than $50 \%$. In a phase-II study performed by Schlumberger et al., which enrolled MTC patients showing either disease progression or symptomatic disease, [113] motesanib achieved PR in only $2 \%$ of subjects, while $81 \%$ achieved SD. Nevertheless, only $47 \%$ of patients experienced SD lasting more than 6 months. Sorafenib efficacy in MTC was evaluated in two small phase-II studies performed by Ahmed et al. [114] and Lam et al. [115], where objective tumour shrinkage was obtained in $25 \%$ and $7 \%$, respectively. Notably, only in Ahmed's trial was disease progression required before entry. In the aforementioned phase-II trial of sunitinib in thyroid cancer, PR was achieved in $43 \%$ of patients with MTC, but the sample size was extremely small [72]. Vandetanib is a KI that targets RET, VEGFR2, VEGFR3 and EGFR. In April 2011 and in February 2012, it was approved for the treatment of adults with symptomatic or progressive MTC by the US FDA and the European Medicines Agency (EMA), respectively. Activity of vandetanib on RET activation in cell lines harbouring RET/MEN2B mutation was first reported by Carlomagno et al. in 2002 [116]. Later on two phase-II studies were performed to assess the activity of vandetanib in patients with hereditary advanced MTC. Wells et al. [117] achieved PR in six out of 30 patients (20\%), while $73 \%$ of subjects achieved SD. Nevertheless, only $53 \%$ of subjects achieved SD lasting at least 6 months. Robinson et al. [118] reported similar results administering vandetanib at a lower dose $(100 \mathrm{mg} /$ day versus $300 \mathrm{mg} /$ day $)$. Therapeutic efficacy of vandetanib was definitely demonstrated in a randomised, double-bind phase-III clinical trial enrolling 331 patients with advanced MTC (ZETA trial, NCT01876784) [119]. Patients were randomised in a 2:1 ratio to vandetanib $300 \mathrm{mg}$ daily versus placebo. Authors clearly showed significant improvements in objective response rate $(45 \%$ versus $13 \% ; P<0.001)$, disease control rate (87 versus 71 ; $P=0.001)$, calcitonin response $(69 \%$ versus $3 \% ; P<0.001)$, and CEA response $(52 \%$ versus $2 \% ; P<0.001)$ in patients treated with vandetanib compared with the placebo group. Despite not reaching the median in the vandetanib group, a significant prolongation of PFS, which was the primary endpoint of the study, was demonstrated in patients who received vandetanib compared with those on placebo, with an estimated 11 -month increase $(30.5 \%$ versus $19.3 \% ; P<0.001)$. Interestingly, a post hoc analysis of RET mutational status found that vandetanib achieved a higher PR rate in sporadic

Table 3

Clinical trials in patients with advanced sporadic and hereditary medullary thyroid carcinoma.

\begin{tabular}{|c|c|c|c|c|}
\hline KI [Ref.] & Type of study & N. of patients & Best TR $(\%)$ & mPFS (months) \\
\hline Imatinib [111] & II & 9 & CR 0 PR 0 SD 40 & - \\
\hline Imatinib [112] & II & 15 & CR 0 PR 0 SD 78 & - \\
\hline Axitinib [69] & II & 11 & CR 0 PR 18 SD 27 & - \\
\hline Motesanib [113] & II & 91 & CR 0 PR 2 SD 81 & 12 \\
\hline Sorafenib [114] & II & 15 & CR 0 PR 25 SD 75 & - \\
\hline Sorafenib [115] & II & 15 & CR 0 PR 7 SD 93 & 17.9 \\
\hline Sunitinib [72] & II & 7 & CR 0 PR 43 SD 29 & - \\
\hline Vandetanib [117] & II & 30 & CR 0 PR 20 SD 73 & 27.9 \\
\hline Vandetanib [118] & II & 19 & CR 0 PR 16 SD 64 & - \\
\hline \multirow[t]{2}{*}{ Vandetanib [119] } & III, RCT, placebo controlled & 231 vandetanib & $\mathrm{CR}+\mathrm{PR}+\mathrm{SD} 87^{*}$ & $30.5^{*}$ \\
\hline & & 100 placebo & $\mathrm{CR}+\mathrm{PR}+\mathrm{SD} 71$ & 19.3 \\
\hline Vandetanib $^{* *}[120]$ & I-II & 15 & $\mathrm{CR}-\mathrm{PR} 47 \mathrm{SD}-$ & - \\
\hline Cabozantinib [122] & $\mathrm{I}$ & 37 & CR 0 PR 35 SD 49 & - \\
\hline \multirow[t]{2}{*}{ Cabozantinib [123] } & III, RCT, placebo controlled & 220 cabozantinib & - & $11.2^{*}$ \\
\hline & & 110 placebo & & 4 \\
\hline Everolimus [99] & II & 9 & CR 0 PR 0 SD 100 & - \\
\hline
\end{tabular}

Abbreviations: KI, kinase-inhibitor; Ref., reference; N., number; TR, tumour response; mPFS, median progression-free survival; CR, complete response; PR, partial response; $\mathrm{SD}$, stable disease; $\mathrm{RCT}$, randomised controlled trials.

* Difference statistically significant.

** Only children (5-12 years) and adolescents (13-18 years) affected with MEN-2B included. 
MTC harbouring the somatic M918T RET mutation than in M918T-negative cases (55\% versus 31\%). Nevertheless, severe and sometimes fatal adverse events were reported in a relevant portion of patients. The most frequent grade- 3 or higher adverse events included diarrhoea $(11 \%)$, hypertension (9\%), QTc prolongation (8\%), fatigue (6\%), decreased appetite (4\%), and rash (4\%). The potential toxicity associated with long-term administration of vandetanib highlights the importance of appropriate selection of patients for treatment with this agent. The relatively indolent behaviour of disease in some patients with MTC who were enrolled onto the Wells trial, which did not require demonstration of progression before entry, is evident from the time to progression of 19.3 months in patients who received the placebo. For these reasons, the risk/benefit ratio of vandetanib is likely to be unfavourable in asymptomatic patients or in patients with a low disease burden who experience slow progression. Importantly, a recent phase-I/II trial by Fox et al. [120] has demonstrated that vandetanib $\left(100 \mathrm{mg} / \mathrm{m}^{2}\right.$ administered once daily for 28 days treatment cycles) was effective in obtaining objective tumour response in a relevant proportion ( $\mathrm{PR}=47 \%$ ) of children and adolescents with MEN2B-related MTC (carrying the germline M918 T mutation). Notably, the authors reported a more favourable toxicity profile compared with that in adults. The KI cabozantinib has been approved by the US FDA (November 2012) for the treatment of progressive, metastatic MTC. Similarly to vandetanib, cabozantinib targets both RET and VEGFRs. In addition, it is active against the receptor of the hepatocyte growth factor c-MET. It is noteworthy that increased co-expression of c-MET and its ligand has been demonstrated in a subset of MTC [48] and could be considered a direct result of RET signalling activity [121]. A preliminary phase-I study of cabozantinib was designed to identify the maximum tolerated dose in patients with a variety of solid tumours, including 37 subjects with MTC [122]. An early analysis reported an increased activity of cabozantinib in these patients, noting a reduction in serum calcitonin in all cases. This prompted the addition of an expansion cohort of patients with MTC within the trial. Among 35 patients with MTC having measurable disease, $25(68 \%)$ had PR or SD for at least 6 months. Importantly, a response was observed in three patients who had been pre-treated with vandetanib or sorafenib, thus supporting the hypothesis of c-MET being an escape pathway from RET and VEFGR inhibition. These findings led directly to a multicentre, randomised, phaseIII trial named EXAM (Efficacy of XL184 in Advanced Medullary Thyroid Cancer, NCT00704730) [123]. This study compared cabozantinib (administered daily at the dose of $140 \mathrm{mg}$ ) with placebo in 330 patients with locally advanced or metastatic MTC. Importantly, only patients with progressive disease were enrolled, and this represents a crucial difference from the vandetanib trial. Median PFS was 11.2 months in the treatment arm versus 4.0 months in the placebo arm, with a statistically significant difference of 7.2 months $(P<0.001)$. Interestingly, PFS was increased independently from prior systemic treatment, prior TKI use, and RET mutational status.
In the light of these results cabozantinib can be considered an effective tool for MTC patients who experience disease progression despite chemotherapy and treatment with other KIs. Nevertheless, an interim analysis of OS (with $44 \%$ of 217 required events) showed no difference between the treatment and the placebo group. Given that this trial did not allow cross-over between groups, this failure in the improvement of OS represents a significant result. The toxicity profile of cabozantinib was generally similar to that of vandetanib, the most frequent grade 3 or higher adverse events being diarrhoea (15.9\%), hand-foot syndrome (12.6\%), fatigue (9.3\%), hypertension (8.4\%), and asthenia (5.6\%). A dedicated analysis of RET and RAS mutations in the phase-III cohort was presented at the ASCO meeting in 2013 [124]. Despite obtaining clinical benefit in all subgroups, cabozantinib achieved a higher median PFS in RET-mutated tumours, as compared with RET wild-type counterparts (60 versus 25 weeks; $P<0.0001)$. Furthermore, patients with the poor prognosis M918T mutation showed a longer PFS as compared with other RET mutations ( 15 versus 9 months; $P=0.009$ ). Finally, patients with RAS mutations achieved similar clinical benefit, as compared with subjects harbouring RET mutations.

\subsubsection{Future perspectives}

Based on the finding that the mTOR pathway is over-expressed in neuroendocrine tumours [93-95], some anecdotal experiences of the activity of everolimus in MTC have been published in recent years. Faggiano et al. [125] reported two cases of patients with advanced MTC under treatment with octreotide - long-acting and repeatable - who were subjected to treatment with everolimus. In both cases a tumour response was observed and a significant reduction in calcitonin levels was obtained. Furthermore, this study demonstrated anti-proliferative activity of everolimus in two different MTC cell lines. Druce et al. [126] described the case of a MEN2A patient with a pluri-metastatic progressive MTC where treatment with everolimus induced a transient radiological stabilisation of disease and a dramatic increase in the calcitonin doubling time. These reports have been confirmed mainly by Lim's trial [99], in which all MTC patients achieved SD. Furthermore, a decrease of $>50 \%$ of calcitonin and CEA levels was observed in $30 \%$ and $44 \%$ of subjects, respectively. Interestingly, data about everolimus in pancreatic neuroendocrine tumours show a higher PFS in patients concomitantly treated with somatostatin analogues [127]. Somatostatin receptors are expressed in $85 \%$ of MTC [48], but previous studies failed to demonstrate any efficacy of somatostatin analogues in this field [128]. Recently, several authors have raised the hypothesis that combining a somatostatin analogue with a KI would have therapeutic value because there are links between somatostatin receptor activation and KI-sensitive signalling pathways. Given that somatostatin receptors $5,1,3$, and 2 are simultaneously expressed in 40-60\% of MTC cases, the multi-somatostatin receptors ligand pasireotide is considered the best indication in this field. To date, a trial assessing the combination of 
pasireotide and everolimus for the treatment of progressive MTC is still recruiting (NCT01625520). Recently, a potent RET inhibitor, ponatinib, is being explored in a phase-II trial, which is also actively recruiting (NCT01838642).

\subsection{Anaplastic thyroid cancer}

To date, anecdotal experiences and small-sample studies have been published on the effects of KIs in ATC. In the paper by Cohen et al. [69], treatment with axitinib led to PR in one out of two ATC patients. In a phase-II study presented at the ASCO meeting in 2009 [129] imatinib led to disease control in six out of eight patients (75\%). By contrast, Savvides et al. [130] reported PR in only two out of 15 subjects (13\%) from a cohort of ATC patients treated with sorafenib, with poor PFS and OS (1.9 and 3.9 months, respectively). Furthermore, a phase-II multicentre trial assessing pazopanib in ATC revealed no responses [83]. Recently, Grande et al. [131] reported an anecdotal experience of sunitinib in ATC, where the treatment induced an almost complete regression of the neck tumour mass despite having no impact on distant metastases. In the aforementioned Lim trial [99], everolimus achieved SD in five out of six ATC patients, and a marked tumour shrinkage was observed in one of them. Ultimately, current data about the activity of KIs in ATC are still partial and contradictory. Thus, larger and dedicated trials are needed to better define the possible role of KIs in this clinical setting. In recent years, several pre-clinical studies demonstrated that a combination of chemotherapeutic agents and KIs showed anti-neoplastic activity in cell lines and xenograft models of ATC [132-135]. Thus, ongoing clinical trials of combined KIs and cytotoxic chemotherapy may give more promising results.

\section{Discussion}

The role of KIs in aggressive forms of thyroid cancer is an evolving field. To date, KIs are considered the most suitable systemic treatment for DTC patients with iodine-refractory disease; these patients comprise the subgroup with the poorer prognosis. Although sorafenib is the only KI approved so far for this specific indication, promising results have been reported regarding several other agents. In particular, the phase-III trial of lenvatinib, results of which were presented at the recent ASCO meeting (2014), has demonstrated excellent efficacy, with both PFS and objective tumour response being even better than with sorafenib. In our opinion, approval of lenvatinib for the treatment of iodine-refractory DTC should be considered by the dedicated agencies. Even if defined as well-tolerated agents, phase-III trials of sorafenib and lenvatinib in DTC have showed a remarkable toxicity, which led to dose reductions in the majority of patients $(64.3 \%$ and $78.5 \%$ for sorafenib and lenvatinib, respectively) and to discontinuation of treatment in a significant proportion of cases ( $18.8 \%$ and $14.2 \%$ for sorafenib and lenvatinib, respectively).
Given that patients with iodine-refractory DTC can be asymptomatic despite evidence of disease progression, the impact of KIs on patients' quality of life should be taken into consideration by clinicians. Furthermore, KI withdrawal may result in a rebound phenomenon, thus inducing a more rapid disease progression [136]. Thus, if and when to begin treatment with KIs in iodine-refractory DTC are key issues. These decisions should consider several aspects, including overall tumour burden, the evidence of disease progression, symptoms, and the possible occurrence of local complications. Up to now, the majority of authors have agreed that patients with a limited tumour burden (few lesions, and/or lesions less than $1 \mathrm{~cm}$ in size) and who are non-progressive should be subjected to active follow-up, without any systemic treatment [67]. To date, chemotherapy is mostly considered an outdated therapeutic approach in DTC. This statement is based mainly on old studies about doxorubicin (which is the only chemotherapeutic agent approved for DTC so far) in which low response rates $(25 \%)$ and considerable toxicities were reported [137]. Nevertheless, recent data may lead to a reconsideration of the role of chemotherapy in this field. In particular, a small retrospective study by Spano et al., including 14 patients with progressive RAI-refractory DTC, has demonstrated that the GEMOX regimen (gemcitabine and oxaliplatin combination) reached a durable objective tumour response in $57.2 \%$ of subjects, whereas SD was reported in $28.6 \%$ [138]. Furthermore, treatment was well tolerated as no grade- 4 toxicities were reported. Although limited by the retrospective nature and small sample size, these data show that both anti-neoplastic activity and safety profile of the GEMOX regimen are comparable with those reported for KIs. Thus, prospective and larger studies are needed to assess the possible role of the GEMOX as well as other chemotherapy regimens in the therapeutic management of RAI-refractory DTC. A new frontier for the use of KIs in iodine-refractory DTC may be opened up by the recent finding that selumetinib can restore iodine avidity and, therefore, clinical response to RAI. Further studies are needed to confirm this aspect definitively, to analyse the RAI-restoring activity of other KIs, and to set up standardised therapeutic algorithms. Two KIs, vandetanib and cabozantinib, have recently been approved for the treatment of advanced, progressive MTC. It is not clear whether one of them should be preferred over the other, as they have similar efficacies and toxicities. Nevertheless, the efficacy of cabozantinib has been proven to be independent of previous treatments with KIs, so we can consider this treatment for those patients experiencing therapeutic escape from vandetanib. However, the considerable toxicity of both compounds, which determines the occurrence of severe adverse events (grade 3 or higher) in a relevant proportion of patients, suggests a selective use in those subjects having a heavy disease burden and/or a strong disease progression. Nevertheless, MTC usually exhibits an indolent behaviour with just a slow progression of disease, even if metastatic. Therefore, further studies are needed to identify therapeutic approaches which could improve the 
risk/benefit ratio in this type of patient. Treatment with the mTOR inhibitor everolimus, alone or in combination with somatostatin analogues, should be considered in this field. Given that benefits of KIs are at best transitory and always followed by a restoration of tumour growth and progression [91], further unsolved questions include how to use KIs sequentially or in combination. Generally, further insights are needed about therapeutic decision-making after the escape from first-line therapy with KIs. Moreover, further studies are needed to correlate the efficacy of each specific compound with genetic factors (e.g. presence of $\mathrm{BRAF}^{\mathrm{V} 600 \mathrm{E}}$ in DTC and RET mutational status in MTC), histological factors (e.g. papillary and follicular DTC histotypes), and medical history (e.g. previous treatment with KIs). This will allow clinicians to perfectly fit the treatment on the basis of the patient's features. Another open question is the actual impact of KIs on OS. Given the relatively long survival of these patients and the fact that the majority of trials allow crossing over from the placebo to the study group, it is difficult to address this aspect. Importantly, the interim analysis of OS in the EXAM trial (cabozantinib in MTC), which did not allow crossing over between groups, reported no significant differences between the treatment and placebo groups. Trials assessing OS as the primary endpoint should be planned to better identify the actual impact of KIs on the clinical outcome of aggressive thyroid cancer. KIs do not significantly impact on clinical features of ATC. Further molecular characterisation leading to different targeted therapy is mandatory in this field.

\section{Conflict of interest statement}

The authors declare that there is no conflict of interest that could be perceived as prejudicing the impartiality of the research reported.

\section{Funding}

This research did not receive any specific grant from any funding agency in the public, commercial or not-for-profit sector.

\section{Reviewers}

Maralyn Druce, M.D., Clinical Reader in Endocrine Medicine, 2nd floor Dominion house, 59 Barts Close, London EC1A7BE, United Kingdom.

Markus Raderer, M.D., Waehringer Guertel 18-20, A1090 Vienna, Austria.

M Xing, M.D., Division of Endocrinology, Diabetes, and Metabolism, Laboratory for Cellular and Molecular Thyroid Research, Johns Hopkins University School of Medicine, 1830 East Monument Street, Baltimore, MD 21287, United States.

\section{References}

[1] Davies L, Welch HG. Increasing incidence of thyroid cancer in the United States, 1973-2002. JAMA 2006;295:2164-7.

[2] Albores-Saavedra J, Henson DE, Glazer E, Schwartz AM. Changing patterns in the incidence and survival of thyroid cancer with follicular phenotype - papillary, follicular, and anaplastic: a morphological and epidemiological study. Endocr Pathol 2007;18:1-7.

[3] Ye L, Santarpia L, Gagel RF. The evolving field of tyrosine kinase inhibitors in the treatment of endocrine tumors. Endocr Rev 2010;31:578-99

[4] Sherman SI. Cytotoxic chemotherapy for differentiated thyroid carcinoma. Clin Oncol (R Coll Radiol) 2010;22:464-8.

[5] Schlumberger MJ. Papillary and follicular thyroid carcinoma. N Engl J Med 1998;338:297-306.

[6] Cooper DS, Doherty GM, Haugen BR, et al. Revised American Thyroid Association management guidelines for patients with thyroid nodules and differentiated thyroid cancer. Thyroid 2009; 19:1167-214.

[7] Eustatia-Rutten CF, Corssmit EP, Biermasz NR, Pereira AM, Romijn JA, Smit JW. Survival and death causes in differentiated thyroid carcinoma. J Clin Endocrinol Metab 2006;91:313-9.

[8] Durante C, Haddy N, Baudin E, et al. Long-term outcome of 444 patients with distant metastases from papillary and follicular thyroid carcinoma: benefits and limits of radioiodine therapy. J Clin Endocrinol Metab 2006;91:2892-9.

[9] Elisei R, Ugolini C, Viola D, et al. BRAF(V600E) mutation and outcome of patients with papillary thyroid carcinoma: a 15-year median follow-up study. J Clin Endocrinol Metab 2008;93:3943-9.

[10] Husain M, Alsever RN, Lock JP, George WF, Katz FH. Failure of medullary carcinoma of the thyroid to respond to doxorubicin therapy. Horm Res 1978;9:22-5.

[11] Kitamura Y, Shimizu K, Nagahama M, et al. Immediate causes of death in thyroid carcinoma: clinicopathological analysis of 161 fatal cases. J Clin Endocrinol Metab 1999;84:4043-9.

[12] Giuffrida D, Gharib H. Anaplastic thyroid carcinoma: current diagnosis and treatment. Ann Oncol 2000;11:1083-9.

[13] Smallridge RC, Marlow LA, Copland JA. Anaplastic thyroid cancer: molecular pathogenesis and emerging therapies. Endocr Relat Cancer 2009;16:17-44.

[14] Rosai J. Poorly differentiated thyroid carcinoma: introduction to the issue, its landmarks, and clinical impact. Endocr Pathol 2004;15:293-6.

[15] Lin JD, Chao TC, Hsueh C. Clinical characteristics of poorly differentiated thyroid carcinomas compared with those of classical papillary thyroid carcinomas. Clin Endocrinol (Oxf) 2007;66:224-8.

[16] Johnson LN. Protein kinase inhibitors: contributions from structure to clinical compounds. Q Rev Biophys 2009;42:1-40.

[17] Bain J, Plater L, Elliott M, et al. The selectivity of protein kinase inhibitors: a further update. Biochem J 2007;408:297-315.

[18] Smith JK, Mamoon NM, Duhe RJ. Emerging roles of targeted small molecule protein-tyrosine kinase inhibitors in cancer therapy. Oncol Res 2004;14:175-225.

[19] Nikiforov YE, Nikiforova MN. Molecular genetics and diagnosis of thyroid cancer. Nat Rev Endocrinol 2011;7:569-80.

[20] Xing M. Molecular pathogenesis and mechanisms of thyroid cancer. Nat Rev Cancer 2013;13:184-99.

[21] Kondo T, Ezzat S, Asa SL. Pathogenetic mechanisms in thyroid follicular-cell neoplasia. Nat Rev Cancer 2006;6:292-306.

[22] McCubrey JA, Steelman LS, Abrams SL, et al. Roles of the RAF/MEK/ERK and PI3K/PTEN/AKT pathways in malignant transformation and drug resistance. Adv Enzyme Regul 2006;46:249-79.

[23] Xing M. BRAF mutation in thyroid cancer. Endocr Relat Cancer 2005; 12:245-62.

[24] Marotta V, Sapio MR, Guerra A, Vitale M. BRAF mutation in cytology samples as a diagnostic tool for papillary thyroid carcinoma. Expert Opin Med Diagn 2011;5:277-90. 
[25] Cohen Y, Xing M, Mambo E, et al. BRAF mutation in papillary thyroid carcinoma. J Natl Cancer Inst 2003;95:625-7.

[26] Soares P, Trovisco V, Rocha AS, et al. BRAF mutations and RET/PTC rearrangements are alternative events in the etiopathogenesis of PTC. Oncogene 2003:22:4578-80.

[27] Kimura ET, Nikiforova MN, Zhu Z, Knauf JA, Nikiforov YE, Fagin JA. High prevalence of BRAF mutations in thyroid cancer: genetic evidence for constitutive activation of the RET/PTC-RASBRAF signaling pathway in papillary thyroid carcinoma. Cancer Res 2003;63:1454-7.

[28] Namba H, Nakashima M, Hayashi T, et al. Clinical implication of hot spot BRAF mutation, V599E, in papillary thyroid cancers. J Clin Endocrinol Metab 2003;88:4393-7.

[29] Nikiforova MN, Kimura ET, Gandhi M, et al. BRAF mutations in thyroid tumors are restricted to papillary carcinomas and anaplastic or poorly differentiated carcinomas arising from papillary carcinomas. J Clin Endocrinol Metab 2003;88:5399-404.

[30] Begum S, Rosenbaum E, Henrique R, Cohen Y, Sidransky D, Westra WH. BRAF mutations in anaplastic thyroid carcinoma: implications for tumor origin, diagnosis and treatment. Mod Pathol 2004;17:1359-63.

[31] Ricarte-Filho JC, Ryder M, Chitale DA, et al. Mutational profile of advanced primary and metastatic radioactive iodine-refractory thyroid cancers reveals distinct pathogenetic roles for BRAF, PIK3CA, and AKT1. Cancer Res 2009;69:4885-93.

[32] Durante C, Puxeddu E, Ferretti E, et al. BRAF mutations in papillary thyroid carcinomas inhibit genes involved in iodine metabolism. J Clin Endocrinol Metab 2007;92:2840-3.

[33] Xing M, Clark D, Guan H, et al. BRAF mutation testing of thyroid fine-needle aspiration biopsy specimens for preoperative risk stratification in papillary thyroid cancer. J Clin Oncol 2009;27:2977-82.

[34] Lee JH, Lee ES, Kim YS. Clinicopathologic significance of BRAF V600E mutation in papillary carcinomas of the thyroid: a metaanalysis. Cancer 2007;110:38-46.

[35] Guerra A, Fugazzola L, Marotta V, et al. A high percentage of BRAFV600E alleles in papillary thyroid carcinoma predicts a poorer outcome. J Clin Endocrinol Metab 2012;97:2333-40.

[36] Santoro M, Carlomagno F, Hay ID, et al. Ret oncogene activation in human thyroid neoplasms is restricted to the papillary cancer subtype. J Clin Invest 1992;89:1517-22.

[37] Marotta V, Guerra A, Sapio MR, Vitale M. RET/PTC rearrangement in benign and malignant thyroid diseases: a clinical standpoint. Eur J Endocrinol 2011;165:499-507.

[38] Castellone MD, De Falco V, Rao DM, et al. The beta-catenin axis integrates multiple signals downstream from RET/papillary thyroid carcinoma leading to cell proliferation. Cancer Res 2009;69: 1867-76.

[39] Miyagi E, Braga-Basaria M, Hardy E, et al. Chronic expression of RET/PTC 3 enhances basal and insulin-stimulated PI3 kinase/AKT signaling and increases IRS-2 expression in FRTL-5 thyroid cells. Mol Carcinog 2004;41:98-107.

[40] Donis-Keller H, Dou S, Chi D, et al. Mutations in the RET protooncogene are associated with MEN 2A and FMTC. Hum Mol Genet 1993;2:851-6.

[41] Elisei R, Romei C, Cosci B, et al. RET genetic screening in patients with medullary thyroid cancer and their relatives: experience with 807 individuals at one center. J Clin Endocrinol Metab 2007;92:4725-9.

[42] Acton DS, Velthuyzen D, Lips CJ, Hoppener JW. Multiple endocrine neoplasia type $2 \mathrm{~B}$ mutation in human RET oncogene induces medullary thyroid carcinoma in transgenic mice. Oncogene 2000;19:3121-5.

[43] Drosten M, Hilken G, Bockmann M, et al. Role of MEN2A-derived RET in maintenance and proliferation of medullary thyroid carcinoma. J Natl Cancer Inst 2004;96:1231-9.

[44] Elisei R, Cosci B, Romei C, et al. Prognostic significance of somatic RET oncogene mutations in sporadic medullary thyroid cancer: a 10-year follow-up study. J Clin Endocrinol Metab 2008;93:682-7.
[45] Brandi ML, Gagel RF, Angeli A, et al. Guidelines for diagnosis and therapy of MEN type 1 and type 2. J Clin Endocrinol Metab 2001;86:5658-71.

[46] Liu Z, Hou P, Ji M, et al. Highly prevalent genetic alterations in receptor tyrosine kinases and phosphatidylinositol 3-kinase/akt and mitogen-activated protein kinase pathways in anaplastic and follicular thyroid cancers. J Clin Endocrinol Metab 2008;93:3106-16.

[47] Wang W, Johansson HE, Bergholm UI, Westermark KM, Grimelius LE. Expression of c-Myc, TGF-alpha and EGF-receptor in sporadic medullary thyroid carcinoma. Acta Oncol 1997;36:407-11.

[48] Papotti M, Olivero M, Volante M, et al. Expression of hepatocyte growth factor (HGF) and its receptor (MET) in medullary carcinoma of the thyroid. Endocr Pathol 2000;11:19-30.

[49] Ezzat S, Huang P, Dackiw A, Asa SL. Dual inhibition of RET and FGFR4 restrains medullary thyroid cancer cell growth. Clin Cancer Res 2005;11:1336-41.

[50] Liu D, Xing M. Potent inhibition of thyroid cancer cells by the MEK inhibitor PD0325901 and its potentiation by suppression of the PI3K and NF-kappaB pathways. Thyroid 2008;18:853-64.

[51] Liu D, Xing J, Trink B, Xing M. BRAF mutation-selective inhibition of thyroid cancer cells by the novel MEK inhibitor RDEA119 and genetic-potentiated synergism with the mTOR inhibitor temsirolimus. Int J Cancer 2010;127:2965-73.

[52] Liu R, Liu D, Trink E, Bojdani E, Ning G, Xing M. The Akt-specific inhibitor MK2206 selectively inhibits thyroid cancer cells harboring mutations that can activate the PI3K/Akt pathway. J Clin Endocrinol Metab 2011;96:E577-85.

[53] Bunone G, Vigneri P, Mariani L, et al. Expression of angiogenesis stimulators and inhibitors in human thyroid tumors and correlation with clinical pathological features. Am J Pathol 1999;155:1967-76.

[54] Jubb AM, Pham TQ, Hanby AM, et al. Expression of vascular endothelial growth factor, hypoxia inducible factor 1alpha, and carbonic anhydrase IX in human tumours. J Clin Pathol 2004;57:504-12.

[55] Turner HE, Nagy Z, Gatter KC, Esiri MM, Wass JA, Harris AL. Proliferation, bcl-2 expression and angiogenesis in pituitary adenomas: relationship to tumour behaviour. Br J Cancer 2000;82:1441-5.

[56] Liu Q, Djuricin G, Staren ED, et al. Tumor angiogenesis in pheochromocytomas and paragangliomas. Surgery 1996;120:938-42, discussion 42-3.

[57] Sasano H, Ohashi Y, Suzuki T, Nagura H. Vascularity in human adrenal cortex. Mod Pathol 1998;11:329-33.

[58] Mitsiades CS, Kotoula V, Poulaki V, et al. Epidermal growth factor receptor as a therapeutic target in human thyroid carcinoma: mutational and functional analysis. J Clin Endocrinol Metab 2006;91:3662-6.

[59] Vieira JM, Santos SC, Espadinha C, et al. Expression of vascular endothelial growth factor (VEGF) and its receptors in thyroid carcinomas of follicular origin: a potential autocrine loop. Eur J Endocrinol 2005;153:701-9.

[60] Yasuoka H, Nakamura Y, Zuo H, et al. VEGF-D expression and lymph vessels play an important role for lymph node metastasis in papillary thyroid carcinoma. Mod Pathol 2005;18:1127-33.

[61] Schiff BA, McMurphy AB, Jasser SA, et al. Epidermal growth factor receptor (EGFR) is overexpressed in anaplastic thyroid cancer, and the EGFR inhibitor gefitinib inhibits the growth of anaplastic thyroid cancer. Clin Cancer Res 2004;10:8594-602.

[62] Hsiao PJ, Lu MY, Chiang FY, Shin SJ, Tai YD, Juo SH. Vascular endothelial growth factor gene polymorphisms in thyroid cancer. J Endocrinol 2007;195:265-70.

[63] Klein M, Vignaud JM, Hennequin V, et al. Increased expression of the vascular endothelial growth factor is a pejorative prognosis marker in papillary thyroid carcinoma. J Clin Endocrinol Metab 2001;86:656-8.

[64] Jo YS, Li S, Song JH, et al. Influence of the BRAF V600E mutation on expression of vascular endothelial growth factor in papillary thyroid cancer. J Clin Endocrinol Metab 2006;91:3667-70.

[65] Lennard CM, Patel A, Wilson J, et al. Intensity of vascular endothelial growth factor expression is associated with increased risk of 
recurrence and decreased disease-free survival in papillary thyroid cancer. Surgery 2001;129:552-8.

[66] Carhill AA, Cabanillas ME, Jimenez C, et al. The noninvestigational use of tyrosine kinase inhibitors in thyroid cancer: establishing a standard for patient safety and monitoring. J Clin Endocrinol Metab 2013;98:31-42.

[67] Xing M, Haugen BR, Schlumberger M. Progress in molecularbased management of differentiated thyroid cancer. Lancet 2013;381:1058-69.

[68] Sherman SI, Wirth LJ, Droz JP, et al. Motesanib diphosphate in progressive differentiated thyroid cancer. N Engl J Med 2008;359:31-42.

[69] Cohen EE, Rosen LS, Vokes EE, et al. Axitinib is an active treatment for all histologic subtypes of advanced thyroid cancer: results from a phase II study. J Clin Oncol 2008;26:4708-13.

[70] Jaume Capdevila JMTP, Aller Javier, Manzano Jose Luis. Axitinib treatment in advanced RAI-resistant differentiated thyroid cancer (DTC) and refractory medullary thyroid cancer (MTC). In: ASCO meeting. 2014.

[71] Marotta V, Guerra A, Zatelli MC, et al. BRAF mutation positive papillary thyroid carcinoma is less advanced when Hashimoto's thyroiditis lymphocytic infiltration is present. Clin Endocrinol (Oxf) 2013.

[72] Carr LL, Mankoff DA, Goulart BH, et al. Phase II study of daily sunitinib in FDG-PET-positive, iodine-refractory differentiated thyroid cancer and metastatic medullary carcinoma of the thyroid with functional imaging correlation. Clin Cancer Res 2010;16: $5260-8$.

[73] Gupta-Abramson V, Troxel AB, Nellore A, et al. Phase II trial of sorafenib in advanced thyroid cancer. J Clin Oncol 2008;26: 4714-9.

[74] Kloos RT, Ringel MD, Knopp MV, et al. Phase II trial of sorafenib in metastatic thyroid cancer. J Clin Oncol 2009;27:1675-84

[75] Cabanillas ME, Waguespack SG, Bronstein Y, et al. Treatment with tyrosine kinase inhibitors for patients with differentiated thyroid cancer: the M. D. Anderson experience. J Clin Endocrinol Metab 2010;95:2588-95.

[76] Hoftijzer H, Heemstra KA, Morreau H, et al. Beneficial effects of sorafenib on tumor progression, but not on radioiodine uptake, in patients with differentiated thyroid carcinoma. Eur J Endocrinol 2009;161:923-31.

[77] Marotta V, Ramundo V, Camera L, et al. Sorafenib in advanced iodine-refractory differentiated thyroid cancer: efficacy, safety and exploratory analysis of role of serum thyroglobulin and FDG-PET. Clin Endocrinol (Oxf) 2012.

[78] Brose MS, Nutting CM, Jarzab B, et al. Sorafenib in radioactive iodine-refractory, locally advanced or metastatic differentiated thyroid cancer: a randomised, double-blind, phase 3 trial. Lancet 2014.

[79] Ikuta K, Yano S, Trung VT, et al. E7080, a multi-tyrosine kinase inhibitor, suppresses the progression of malignant pleural mesothelioma with different proangiogenic cytokine production profiles. Clin Cancer Res 2009;15:7229-37.

[80] Okamoto K, Kodama K, Takase K, et al. Antitumor activities of the targeted multi-tyrosine kinase inhibitor lenvatinib (E7080) against RET gene fusion-driven tumor models. Cancer Lett 2013;340: $97-103$.

[81] Sherman SIJB, Cabanillas ME, Licitra LF, et al. A phase II trial of the multi-targeted kinase inhibitor, Lenvatinib (E7080), in advanced radioiodine-refractory differentiated thyroid cancer (DTC). J Clin Oncol 2011;29:5503 [Meeting Abstracts].

[82] Martin Schlumberger MT, Lori JW, Robinson B, et al. A phase 3, multicenter, double-blind, placebo-controlled trial of lenvatinib (E7080) in patients with 131I-refractory differentiated thyroid cancer (SELECT). In: ASCO meeting. 2014.

[83] Bible KC, Suman VJ, Molina JR, et al. Efficacy of pazopanib in progressive, radioiodine-refractory, metastatic differentiated thyroid cancers: results of a phase 2 consortium study. Lancet Oncol 2010;11:962-72.
[84] Marotta V, Franzese MD, Del Prete M, et al. Targeted therapy with kinase inhibitors in aggressive endocrine tumors. Expert Opin Pharmacother 2013;14:1187-203.

[85] Leboulleux S, Bastholt L, Krause T, et al. Vandetanib in locally advanced or metastatic differentiated thyroid cancer: a randomised, double-blind, phase 2 trial. Lancet Oncol 2012;13:897-905.

[86] Faivre S, Zappa M, Vilgrain V, et al. Changes in tumor density in patients with advanced hepatocellular carcinoma treated with sunitinib. Clin Cancer Res 2011;17:4504-12.

[87] Falchook GS, Long GV, Kurzrock R, et al. Dabrafenib in patients with melanoma, untreated brain metastases, and other solid tumours: a phase 1 dose-escalation trial. Lancet 2012;379:1893-901.

[88] Sosman JA, Kim KB, Schuchter L, et al. Survival in BRAF V600mutant advanced melanoma treated with vemurafenib. N Engl J Med 2012;366:707-14.

[89] Kim KB, Cabanillas ME, Lazar AJ, et al. Clinical responses to vemurafenib in patients with metastatic papillary thyroid cancer harboring BRAF(V600E) mutation. Thyroid 2013;23:1277-83.

[90] Brose MS, Cabanillas ME, Cohen EEW, et al. An open-label, multicenter phase 2 study of the BRAF inhibitor vemurafenib in patients with metastatic or unresectable papillary thyroid cancer (ptc) positive for the BRAF V600 mutation and resistant to radioactive iodine. In: European Cancer Congress. 2013

[91] Bergers G, Hanahan D. Modes of resistance to anti-angiogenic therapy. Nat Rev Cancer 2008;8:592-603.

[92] Vignot S, Faivre S, Aguirre D. Raymond E. mTOR-targeted therapy of cancer with rapamycin derivatives. Ann Oncol 2005;16:525-37.

[93] Shida T, Kishimoto T, Furuya M, Nikaido T, Koda K, Takano S, et al. Expression of an activated mammalian target of rapamycin (mTOR) in gastroenteropancreatic neuroendocrine tumors. Cancer Chemother Pharmacol 2010;65:889-93.

[94] Righi L, Volante M, Rapa I, Tavaglione V, Inzani F, Pelosi G, et al. Mammalian target of rapamycin signaling activation patterns in neuroendocrine tumors of the lung. Endocr Relat Cancer 2010;17:977-87.

[95] von Wichert G, Jehle PM, Hoeflich A, Koschnick S, Dralle H, Wolf E, et al. Insulin-like growth factor-I is an autocrine regulator of chromogranin A secretion and growth in human neuroendocrine tumor cells. Cancer Res 2000;60:4573-81.

[96] Ragazzon B, Assie G, Bertherat J. Transcriptome analysis of adrenocortical cancers: from molecular classification to the identification of new treatments. Endocr Relat Cancer 2011;18:R15-27.

[97] De Martino MC, van Koetsveld PM, Pivonello R, Hofland LJ. Role of the mTOR pathway in normal and tumoral adrenal cells. Neuroendocrinology 2010;92(Suppl. 1):28-34

[98] Jensen RT, Berna MJ, Bingham DB, Norton JA. Inherited pancreatic endocrine tumor syndromes: advances in molecular pathogenesis, diagnosis, management, and controversies. Cancer 2008;113:1807-43.

[99] Lim SM, Chang H, Yoon MJ, et al. A multicenter, phase II trial of everolimus in locally advanced or metastatic thyroid cancer of all histologic subtypes. Ann Oncol 2013;24:3089-94.

[100] Lorch HBN, Ruan DT, Janne PA, et al. A phase II study of everolimus in patients with aggressive RAI refractory (RAIR) thyroid cancer (TC). In: ASCO meeting. 2013.

[101] Carracedo A, Ma L, Teruya-Feldstein J, et al. Inhibition of mTORC1 leads to MAPK pathway activation through a PI3K-dependent feedback loop in human cancer. J Clin Invest 2008;118:3065-74.

[102] Sherman EJHA, Fury MG, Baxi SS, et al. Phase II study of everolimus and sorafenib for the treatment of metastatic thyroid cancer. In: ASCO meeting. 2013

[103] Liu YY, van der Pluijm G, Karperien M, et al. Lithium as adjuvant to radioiodine therapy in differentiated thyroid carcinoma: clinical and in vitro studies. Clin Endocrinol (Oxf) 2006;64:617-24.

[104] Handkiewicz-Junak D, Roskosz J, Hasse-Lazar K, et al. 13-cisretinoic acid re-differentiation therapy and recombinant human thyrotropin-aided radioiodine treatment of non-Functional metastatic 
thyroid cancer: a single-center, 53-patient phase 2 study. Thyroid Res 2009;2:8.

[105] Crews CM, Alessandrini A, Erikson RL. The primary structure of MEK, a protein kinase that phosphorylates the ERK gene product. Science 1992;258:478-80.

[106] Liu D, Hu S, Hou P, Jiang D, Condouris S, Xing M. Suppression of BRAF/MEK/MAP kinase pathway restores expression of iodidemetabolizing genes in thyroid cells expressing the V600E BRAF mutant. Clin Cancer Res 2007;13:1341-9.

[107] Chakravarty D, Santos E, Ryder M, et al. Small-molecule MAPK inhibitors restore radioiodine incorporation in mouse thyroid cancers with conditional BRAF activation. J Clin Invest 2011;121: 4700-11.

[108] Hayes DN, Lucas AS, Tanvetyanon T, et al. Phase II efficacy and pharmacogenomic study of Selumetinib (AZD6244; ARRY-142886) in iodine-131 refractory papillary thyroid carcinoma with or without follicular elements. Clin Cancer Res 2012;18:2056-65.

[109] Ho AL, Grewal RK, Leboeuf R, et al. Selumetinib-enhanced radioiodine uptake in advanced thyroid cancer. N Engl J Med 2013;368:623-32.

[110] Cohen MS, Hussain HB, Moley JF. Inhibition of medullary thyroid carcinoma cell proliferation and RET phosphorylation by tyrosine kinase inhibitors. Surgery 2002;132:960-6, discussion 6-7.

[111] Frank-Raue K, Fabel M, Delorme S, Haberkorn U, Raue F. Efficacy of imatinib mesylate in advanced medullary thyroid carcinoma. Eur J Endocrinol 2007;157:215-20.

[112] de Groot JW, Zonnenberg BA, van Ufford-Mannesse PQ, et al. A phase II trial of imatinib therapy for metastatic medullary thyroid carcinoma. J Clin Endocrinol Metab 2007;92:3466-9.

[113] Schlumberger MJ, Elisei R, Bastholt L, et al. Phase II study of safety and efficacy of motesanib in patients with progressive or symptomatic, advanced or metastatic medullary thyroid cancer. J Clin Oncol 2009;27:3794-801.

[114] Ahmed M, Barbachano Y, Riddell A, et al. Analysis of the efficacy and toxicity of sorafenib in thyroid cancer: a phase II study in a UK based population. Eur J Endocrinol 2011;165:315-22.

[115] Lam ET, Ringel MD, Kloos RT, et al. Phase II clinical trial of sorafenib in metastatic medullary thyroid cancer. J Clin Oncol 2010;28:2323-30.

[116] Carlomagno F, Vitagliano D, Guida T, et al. ZD6474, an orally available inhibitor of KDR tyrosine kinase activity, efficiently blocks oncogenic RET kinases. Cancer Res 2002;62:7284-90.

[117] Wells Jr SA, Gosnell JE, Gagel RF, et al. Vandetanib for the treatment of patients with locally advanced or metastatic hereditary medullary thyroid cancer. J Clin Oncol 2010;28:767-72.

[118] Robinson BG, Paz-Ares L, Krebs A, Vasselli J, Haddad R. Vandetanib $(100 \mathrm{mg})$ in patients with locally advanced or metastatic hereditary medullary thyroid cancer. J Clin Endocrinol Metab 2010;95: 2664-71.

[119] Wells Jr SA, Robinson BG, Gagel RF, et al. Vandetanib in patients with locally advanced or metastatic medullary thyroid cancer: a randomized, double-blind phase III trial. J Clin Oncol 2012;30:134-41.

[120] Fox E, Widemann BC, Chuk MK, et al. Vandetanib in children and adolescents with multiple endocrine neoplasia type $2 \mathrm{~B}$ associated medullary thyroid carcinoma. Clin Cancer Res 2013;19:4239-48.

[121] Costantini F. Genetic controls and cellular behaviors in branching morphogenesis of the renal collecting system. Wiley Interdiscip Rev Dev Biol 2012;1:693-713.

[122] Kurzrock R, Sherman SI, Ball DW, et al. Activity of XL184 (Cabozantinib), an oral tyrosine kinase inhibitor, in patients with medullary thyroid cancer. J Clin Oncol 2011;29:2660-6.

[123] Elisei R, Schlumberger MJ, Muller SP, et al. Cabozantinib in progressive medullary thyroid cancer. J Clin Oncol 2013;31:3639-46.

[124] Sherman SICEE, Schoffski P, Elisei R, et al. Efficacy of cabozantinib (Cabo) in medullary thyroid cancer (MTC) patients with RAS or RET mutations: results from a phase III study. In: ASCO meeting. 2013.
[125] Faggiano A, Ramundo V, Dicitore A, et al. Everolimus is an active agent in medullary thyroid cancer: a clinical and in vitro study. J Cell Mol Med 2012;16:1563-72.

[126] Druce M, Chung TT, Grozinsky-Glasberg S, Gross DJ, Grossman AB. Preliminary report of the use of everolimus in a patient with progressive medullary thyroid carcinoma. Clin Endocrinol (Oxf) 2012;77:154-5.

[127] Yao JC, Lombard-Bohas C, Baudin E, et al. Daily oral everolimus activity in patients with metastatic pancreatic neuroendocrine tumors after failure of cytotoxic chemotherapy: a phase II trial. J Clin Oncol 2010;28:69-76.

[128] Vainas I, Koussis C, Pazaitou-Panayiotou K, et al. Somatostatin receptor expression in vivo and response to somatostatin analog therapy with or without other antineoplastic treatments in advanced medullary thyroid carcinoma. J Exp Clin Cancer Res 2004;23:549-59.

[129] Ha HT, et al. Phase II trial evaluating imatinib (I) in patients (pts) with anaplastic thyroid carcinoma (ATC). In: ASCO meeting. 2009.

[130] Savvides P, Nagaiah G, Lavertu P, et al. Phase II trial of sorafenib in patients with advanced anaplastic carcinoma of the thyroid. Thyroid 2013;23:600-4.

[131] Grande E, Capdevila J, Diez JJ, Longo F, Carrato A. A significant response to sunitinib in a patient with anaplastic thyroid carcinoma. J Res Med Sci 2013;18:623-5.

[132] Kim S, Prichard CN, Younes MN, et al. Cetuximab and irinotecan interact synergistically to inhibit the growth of orthotopic anaplastic thyroid carcinoma xenografts in nude mice. Clin Cancer Res 2006;12:600-7.

[133] Libertini S, Iacuzzo I, Perruolo G, et al. Bevacizumab increases viral distribution in human anaplastic thyroid carcinoma xenografts and enhances the effects of E1A-defective adenovirus d1922-947. Clin Cancer Res 2008;14:6505-14.

[134] Nappi TC, Salerno P, Zitzelsberger H, Carlomagno F, Salvatore G, Santoro M. Identification of Polo-like kinase 1 as a potential therapeutic target in anaplastic thyroid carcinoma. Cancer Res 2009:69:1916-23

[135] Wang Z, Chakravarty G, Kim S, et al. Growth-inhibitory effects of human anti-insulin-like growth factor-I receptor antibody (A12) in an orthotopic nude mouse model of anaplastic thyroid carcinoma. Clin Cancer Res 2006;12:4755-65.

[136] Mancuso MR, Davis R, Norberg SM, et al. Rapid vascular regrowth in tumors after reversal of VEGF inhibition. J Clin Invest 2006;116:2610-21.

[137] Sherman SI. Early clinical studies of novel therapies for thyroid cancers. Endocrinol Metab Clin North Am 2008;37:511-24, xi.

[138] Spano JP, Vano Y, Vignot S, et al. GEMOX regimen in the treatment of metastatic differentiated refractory thyroid carcinoma. Med Oncol 2012;29:1421-8.

\section{Biographies}

V. Marotta received his Medical Doctor degree in 2007 at the Federico II University, Naples (Italy). Thereafter, he earned the speciality in Endocrinology and Metabolic Diseases at the Federico II University, Naples (Italy). He is currently a Ph.D. student in molecular oncology and endocrinology at the Department of Clinical Medicine and Surgery, University "Federico II", Naples (Italy). He is the author more than 25 articles in high-impact peer-reviewed journals. He is a referee for several peer-reviewed journals (Minerva Endocrinologica, Tumori, Endocrine). His main focus is translational and clinical research in the area of thyroid cancer and neuroendocrine tumours. $\mathrm{He}$ is a 
member of several scientific societies: Società Italiana di Endocrinologia, the European Society of Endocrinology, and the European Society of Neuroendocrine Tumours.

C. Sciammarella received her degree in biological sciences in 2012 at the Federico II University, Naples (Italy). She is currently working as a molecular biologist at the Department of Clinical Medicine and Surgery, Federico II University, Naples (Italy). Her research is focused on molecular pathogenesis of endocrine cancer. She is a member of Italian Society of Endocrinology (SIE).

M. Vitale M.D. is an associate professor of endocrinology at the University of Salerno (Italy) and director of the Division of Thyroid Disease at the University Hospital Ruggi D'Aragona, Salerno (Italy). He is a leading expert in thyroid cancer and the principal investigator in several ongoing clinical studies. Dr. Vitale earned his Medical Doctor degree and Speciality of Endocrinology at the Federico II University, Naples (Italy) in 1982 and 1985, respectively. He has published over 60 articles about thyroid cancer and BRAF mutation in such journals as the Clinical Cancer Research, Cell Cycle, The Journal of Clinical Endocrinology \& Metabolism, and Endocrine-Related Cancer. He currently serves as a member of the educational board of the Italian Society of Endocrinology and of the Italian Thyroid Association.

A. Colao M.D. is a full professor of endocrinology and coordinator of the Course of Endocrinology and Gastroenterology for the School of Medicine and Surgery, "Federico II" University of Naples (Italy). She is a member of the Consiglio Nazionale Garanti per la Ricerca at the University and Research Ministry, Italian Continuous Medical Education Commission, and of the Commission for the Italian Research Plan. She is president of the Regional Network Project Endocrinologia Regione Campania and coordinator of National and International research projects. She has published 600 full papers in international journals; more than 100 chapters in books and monographs. She scores 40th in the list of top Italian scientists. Current areas of research interest include the molecular basis and clinical use of innovative therapies for the treatment of sporadic and hereditary forms of endocrine cancers (including thyroid cancer and neuroendocrine tumours).

A. Faggiano M.D., Ph.D. received his Medical Doctor degree in 1997 at the Federico II University, Naples (Italy). Thereafter, he earned the speciality in endocrinology and metabolic diseases in 2002 at the Federico II University, Naples (Italy). He then completed a European University Research Diploma in Clinical Oncology (DUERCC) in 2003 at the Paris-SUD University, Paris (France). He received his doctorate in molecular oncology and endocrinology in 2007 (research studies performed at the Federico II University of Naples and at the Gustave-Roussy Institute, Villejuif, France). He is a member of the following scientific societies: Italian Society of Endocrinology (SIE), Association of Medical Endocrinologists (AME), Italian Society of Diabetology (SID), European Society of Endocrinology (ESE), European Neuroendocrine Association (ENEA), European Neuroendocrine Tumour Society (ENETS), and Societe Française d'Endocrinologie (SFE). He is author of about 100 publications in peer-reviewed journals about neuroendocrine tumours. 